\title{
PENGARUH STRATEGI PEMBELAJARAN PROBLEM BASED LEARNING (PBL) DAN GROUP INVESTIGATION (GI) TERHADAP SIKAP ILMIAH DI MAN KABANJAHE
}

\author{
Iskandar Dinata Ginting1), Ely Djulia2), Tumiur Gultom²) \\ 1)Guru MAN Kabanjahe, Tanah Karo Sumatera Utara Email: dinata.krina@gmail.com \\ 2) Dosen Program Studi Pendidikan Biologi Program Pascasarjana \\ Universitas Negeri Medan.
}

\begin{abstract}
Abstrak : Penelitian ini bertujuan untuk mengetahui pengaruh strategi pembelajaran terhadap Sikap ilmiah. Metode penelitian menggunakan kuasi eksperimen dengan sampel penelitian sebanyak 3 kelas ditentukan secara acak dengan teknik cluster random sampling. Kelas A dibelajarkan dengan strategi pembelajaran Problem Based Learning, kelas B dengan strategi pembelajaran Group Investigation dan kelas C (Kontrol) menggunakan strategi pembelajaran Konvensional. Instrumen penelitian menggunakan tes Sikap ilmiah dalam bentuk uraian lembar observasi. Teknik analisis data dengan Analisis Covariat (ANACOVA) pada taraf signifikan $a=0,05$ dengan bantuan SPSS 24. Hasil penelitian menunjukkan ada pengaruh signifikan strategi pembelajaran terhadap Sikap ilmiah $(\mathrm{F}=3,673 ; \mathrm{P}=0,029)$. Sebagai tindak lanjut dari hasil penelitian ini diharapkan kepada guru untuk dapat menerapkan strategi Problem Based Learning (PBL) pada materi Ekologi dalam upaya meningkatkan Sikap ilmiah.
\end{abstract}

Kata Kunci : Sikap ilmiah, Strategi Problem Based Learning, Group Investigation dan Pembelajaran Konvensional

\section{PENDAHULUAN}

Materi Ekologi merupakan materi yang mempelajari hubungan timbal balik antara makhluk hidup dan (kondisi) alam sekitarnya (lingkungannya) (KBBI, 1997). Ekologi dipandang sebagai materi yang sangat penting karena materi ini berhubungan langsung dengan kehidupan sehari-hari, sehingga ketika mempelajarinya akan lebih berkesan dan bermakna di benak peserta didik karena dapat secara langsung ke alam nyata. Selain itu kerusakan ekologi dirasakan oleh hampir seluruh manusia. Segala upaya dipandang mutlak dilakukan demi mencegah agar kerusakan ekologi tidak semakin parah, terutama oleh dunia pendidikan.

Hasil wawancara tidak terstruktur kepada wakil bidang kurikulum di sekolah tersebut didapatkan informasi bahwa pembelajaran biologi disekolah tersebut jarang sekali mengadakan praktikum, hal ini dikarenakan sekolah tersebut belum memilki laboratorium biologi. Namun, praktikum hanya satu atau dua kali dalam satu semesternya, hal ini dilakukan jika ada tuntutan ujian semester yang mengharuskan adanya penilaian praktikum atau laporan guru tentang kegiatan pembelajaran kepada kepala sekolah. Berikut ini merupakan nilai praktikum biologi pada materi ekologi pada tiga tahun terakhir yaitu dengan rata-rata nilai pada tahun ajaran 2012/2013 adalah 74 dan pada tahun ajaran 2013/2014 nilainya menurun menjadi 73 serta tahun ajaran 2014/2015 adalah 76 Beberapa hasil temuan diatas mengindikasikan bahwa peserta didik di MAN Kabanjahe memilki kemampuan keterampilan proses yang rendah dalam pembelajaran biologi khususnya materi ekologi.

Senada dengan temuan diatas, hasil belajar biologi pada materi ekologi peserta 
didik di MAN Kabanjahe juga masih kurang memuaskan. Hal ini terlihat rata-rata nilai ujian akhir semester biologi kelas $\mathrm{X}$ masih dibawah nilai KKM yang ditetapkan oleh sekolah, yaitu: (1) Pada tahun ajaran 2012/2013 KKM yang ditetapkan adalah 80 nilai rata-rata yang didapatkan adalah 70 . (2) Tahun ajaran 2013/2014 KKM yang ditetapkan 80, nilainya rata-rata 72 serta, (3) Tahun ajaran 2014/2015 KKM 81 nilai rata-rata adalah 74 (Data hasil penilaian langsung dari guru mata pelajaran Biologi).

MAN Kabanjahe merupakan sekolah agama yang sudah memiliki ruangan laboratorium, perlengkapan untuk mengadakan praktikum sudah ada walapun belum terlalu lengkap karena untuk laboratorium tersebut masih bersatu dengan mata pelajaran lain seperti Kimia dan Fisika. Disamping itu, sekolah ini terletak di area pertanian yang masih asri sehingga lingkungan sekitar dapat di jadikan sebagai laboratorium alami, sesuai dengan topik pembelajaran yang akan dipelajari. Akan tetapi guru jarang sekali menggunakannya. Guru lebih sering menyampaikan materi dengan memberi ceramah dan pemberian tugas kepada peserta didik. Padahal, menurut Mutiara (2011) objek kajian biologi berkaitan dengan makhluk hidup dan alam sekitar, sehingga bukan hanya berupa fakta, prinsip, ataupun konsep, tetapi suatu proses penemuan. Proses pembelajaran biologi menekankan pada pemberian pengalaman langsung untuk mengembangkan kompetensi agar peserta didik mampu memahami alam sekitar. Oleh karena itu, pembelajaran biologi idealnya dipelajari secara ilmiah untuk meningkatkan hasil belajar.

Selanjutnya dalam hal proses penemuan tersebut melatih peserta didik dalam tiga hal komponen sains yaitu sikap, proses dan produk. Pada dasarnya pelajaran biologi berupaya untuk membekali peserta didik dengan berbagai kemampuan tentang cara mengetahui dan cara mengerjakan yang dapat membantu peserta didik untuk memahami alam sekitar. Sehingga melalui tiga komponen tersebut peserta didik dilatih untuk mencapai produk materi dengan menerapkan sikap yang ilmiah serta membutuhkan sikap ilmiah yang menunjang.

Ahmad dan Rubba (1983), mengungkapkan bahwa sikap ilmiah merupakan keterampilan kognitif yang digunakan oleh saintis sebagai pendekatan sistematik dalam penyelesaian masalah, didukung oleh Yunus dan Hashim (2007) menyatakan bahwa sikap ilmiah akan meningkatkan kemampuan berpikir kritis, prestasi dan sikap siswa dalam belajar.

$$
\text { Warsono dan Hariyanto, (2013) }
$$
menetapkan delapan kemampuan Sikap ilmiah yaitu mengamati, menafsirkan pengamatan, meramalkan, menggunakan alat dan bahan, menerapkan konsep, merencanakan percobaan, berkomunikasi, dan mengajukan pertanyaan.

Selain itu, strategi pembelajaran juga merupakan usaha untuk memperoleh kesuksesan dan keberhasilan dalam mencapai tujuan pembelajaran. Panjaitan, B (2006) menyatakan bahwa pembelajaran akan lebih efektif jika strategi pembelajaran yang digunakan sesuai dengan karakteristik pelajar dan materi yang dibelajarkan. Gagasan lainnya oleh Dick, W dan Carey, L (2005) yang menyatakan bahwa strategi pembelajaran adalah suatu set materi dan prosedur pembelajaran yang digunakan secara bersamasama untuk mencapai tujuan pembelajaran. Diantara strategi pembelajaran yang dapat membantu peserta didik untuk mencapai tujuan pembelajaran adalah strategi pembelajaran Problem Based Learning (PBL) dan Group Investigation (GI).

Strategi Problem Based Learning (PBL) dapat diartikan sebagai rangkaian aktivitas pembelajaran yang menekankan kepada proses penyelesaian masalah yang dihadapi secara ilmiah (Sanjaya, 2008). Lebih lanjut Kunandar (2009) menyatakan bahwa Problem Based Learning (PBL) adalah pembelajaran yang menggunakan masalah dunia nyata sebagai suatu konteks bagi siswa untuk belajar tentang cara berfikir kritis dan keterampilan pemecahan masalah. 
Sedangkan dari segi paedagogis menurut Rusman (2010), strategi pembelajaran problem based learning pada teori belajar konstruktivisme memiliki ciri-ciri, sebagai berikut: (1) Pemahaman diperoleh dari interaksi dengan skenario permasalahan dan lingkungan belajar; (2) pergulatan dengan masalah dan proses inquiry masalah menciptakan disonansi kognitif yang menstimular belajar; dan (3) pengetahuan terjadi melalui proses kolaborasi negosiasi sosial dan evaluasi terhadap keberadaan sebuah sudut pandang.

Menurut Sudewi, dkk (2014) menyatakan bahwa strategi pembelajaran yang dapat mengaitkan pengalaman dalam kehidupan nyata peserta didik dengan materi pelajaran pelajaran sains terutama Biologi serta dapat merangsang dan melatih keterampilan berpikir tingkat tinggi peserta didik dari aspek terendah sampai aspek tertinggi taksonomi Bloom adalah strategi pembelajaran kooperatif tipe Group Investigation (GI).

Menurut penelitian $\mathrm{Oh}$ dan Shin (2005), strategi pembelajaran group investigation dapat menjadikan para siswa menjadi komunitas inkuiri yang artinya setiap siswa menjadi investigator untuk kepentingan pembelajaran di kelas. Dalam pembelajaran ini kegiatan aktif dengan pengetahuan dibangun sendiri oleh siswa dan mereka bertanggung jawab atas hasil pembelajarannya.

\section{METODE PENELITIAN}

Penelitian ini dilaksanakan di MAN Kabanjahe Jln. Samura Go Madrasah No.06 Kode Pos 22112. Pada semester genap tahun ajaran 2015 - 2016 dari bulan April sampai dengan bulan Juni 2016. Penelitian ini disesuaikan dengan kelender pendidikan dan jadwal proses belajar mengajar yang terdapat di MAN Kabanjahe.

\section{TEKNIK PENGUMPULAN DATA}

Teknik pengumpulan data yang digunakan dalam penelitian ini adalah teknik tes yang berfungsi untuk mengukur kemampuan Sikap ilmiah dalam bentuk soal essay tes sebanyak 12 soal. Tes ini dilakukan dua kali yaitu sebelum perlakuan yang tujuannya untuk mengetahui kemampuan awal peserta didik dan setelah perlakuan untuk mengetahui kemampuan peserta didik setelah adanya perlakuan. Selain itu ada juga lembar observasi yang harus diisi pada tiap berlangsungnya proses pembelajaran setiap pertemuannya yang tujuannya adalah untuk melihat aktivitas yang dilakukan oleh guru dan siswa selama proses pembelajaran berlangsung.

\section{TEKNIK ANALISIS DATA}

Teknik analisis data yang digunakan dalam penelitian ini adalah teknik analisis inferensial. Analisis statisik inferensial yang dilakukan untuk menguji hipotesis. Sebelum pengujian hipotesis, terlebih dahulu dilakukan uji prasyarat terhadap data yang dikumpulkan yaitu dengan menggunakan uji normalitas dan homogenitas. Uji normalitas dimaksudkan untuk menguji apakah data sampel yang diperoleh dari populasi memiliki sebaran yang berdistribusi normal. Uji normalitas dilakukan dengan pendekatan Kolmogoro - Smirnov.

Sedangkan uji homogenitas dimaksudkan untuk menguji apakah kelompok - kelompok sampel berasal populasi yang sama, artinya penyebarannya dalam populasi bersifat homogen. Uji homogenitas data dilakukan dengan pendekatan Levene's Test. Setelah prasyarat terpenuhi selanjutnya dilakukan pengujian hipotesis penelitian dengan menggunakan Analisis Kovariat (ANACOVA) pada taraf $\alpha=5 \%$. Apabila hasil uji statistik menunjukkan pengaruh yang signifikan, maka analisis dilanjutkan dengan uji tukey's dengan menggunakan SPSS 24.0.

\section{HASIL PENELITIAN \\ Sikap Ilmiah}

Sebelum dilaksankannya kegiatan pembelajaran maka terlebih dahulu peneliti melihat kemampuan awal siswa (pretes) dan setelah kegiatan pembelajaran dilaksanakan 
(postes), sehingga diperoleh data hasil penelitian Sikap ilmiah siswa.

Tabel 1. Data Hasil Penelitian (Sikap ilmiah)

\begin{tabular}{|c|c|c|c|c|c|c|}
\hline \multirow{2}{*}{ No } & \multicolumn{2}{|c|}{$\begin{array}{c}\text { Kelas A } \\
\text { (PBL) }\end{array}$} & \multicolumn{2}{c|}{$\begin{array}{c}\text { Kelas B } \\
\text { (GI) }\end{array}$} & \multicolumn{2}{c|}{$\begin{array}{c}\text { Kelas C } \\
\text { (Konvensional) }\end{array}$} \\
\cline { 2 - 7 } & Pre & Pos & Pre & Pos & Pre & Pos \\
\hline 1 & 91 & 93 & 80 & 86 & 80 & 83 \\
\hline 2 & 92 & 94 & 92 & 95 & 82 & 83 \\
\hline 3 & 92 & 93 & 92 & 92 & 80 & 83 \\
\hline 4 & 96 & 98 & 91 & 94 & 81 & 83 \\
\hline 5 & 93 & 93 & 81 & 86 & 81 & 85 \\
\hline 6 & 95 & 96 & 93 & 93 & 80 & 82 \\
\hline 7 & 95 & 95 & 95 & 95 & 81 & 91 \\
\hline 8 & 93 & 96 & 90 & 90 & 80 & 90 \\
\hline 9 & 87 & 90 & 89 & 89 & 80 & 83 \\
\hline 10 & 87 & 89 & 90 & 90 & 88 & 88 \\
\hline 11 & 88 & 91 & 91 & 91 & 83 & 87 \\
\hline 12 & 91 & 91 & 92 & 92 & 83 & 85 \\
\hline 13 & 83 & 85 & 92 & 92 & 80 & 85 \\
\hline 14 & 84 & 85 & 87 & 87 & 84 & 84 \\
\hline 15 & 85 & 88 & 93 & 93 & 80 & 87 \\
\hline 16 & 93 & 95 & 95 & 95 & 81 & 83 \\
\hline 17 & 94 & 95 & 95 & 95 & 81 & 84 \\
\hline 18 & 92 & 95 & 81 & 85 & 87 & 87 \\
\hline 19 & 92 & 97 & 87 & 87 & 87 & 87 \\
\hline 20 & 91 & 91 & 87 & 87 & 80 & 91 \\
\hline 21 & 86 & 90 & 80 & 85 & 80 & 84 \\
\hline 22 & 93 & 95 & 80 & 85 & 80 & 90 \\
\hline 23 & 95 & 96 & 80 & 85 & 81 & 87 \\
\hline 24 & 90 & 94 & 81 & 83 & 83 & 85 \\
\hline 25 & 87 & 90 & 81 & 83 & 81 & 92 \\
\hline 26 & 89 & 91 & 93 & 93 & 81 & 94 \\
\hline 27 & 93 & 93 & 94 & 94 & & \\
\hline 28 & 93 & 95 & 90 & 90 & & \\
\hline 29 & 94 & 95 & 80 & 83 & & \\
\hline 30 & 92 & 97 & & & & \\
\hline 31 & 92 & 95 & & & & \\
\hline 32 & 95 & 95 & & & & \\
\hline 33 & 94 & 94 & & & & \\
\hline 34 & 93 & 95 & & & & \\
\hline 35 & 95 & 96 & & & & \\
\hline & & & & & \\
\hline
\end{tabular}

Data kemampuan awal (pretes) sikap ilmiah siswa pada kelas Problem Based Learning (PBL) diperoleh nilai tertinggi 96 dan terendah 83 dengan \pm SD 91,29 $\pm 3,426$, serta memiliki sebaran data yang terdistribusi normal $(\mathrm{Z}=0,211 ; \mathrm{P}=0,000)$. Pada kelas Strategi Group Investigation (GI) diperoleh nilai tertinggi 95 dan nilai terendah 80 dengan \pm SD $88,00 \pm 5,581$, serta memiliki sebaran data yang terdistribusi normal $(\mathrm{Z}=0,205 ; \mathrm{P}=$ 0,003). Dan pada kelas konvensional diperoleh nilai tertinggi 88 dan nilai terendah 80 dengan \pm SD $81,85 \pm 2,344$, serta memiliki sebaran data yang terdistribusi normal $(Z=0,295 ; P=0,000)$.

Data hasil akhir (pretes) sikap ilmiah siswa pada kelas Problem Based Learning (PBL) diperoleh nilai tertinggi 98 dan terendah 85 dengan \pm SD 93,23 $\pm 3,172$, serta memiliki sebaran data yang terdistribusi normal $(\mathrm{Z}=0,197 ; \mathrm{P}=0,001)$. Pada kelas Strategi Group Investigation (GI) diperoleh nilai tertinggi 95 dan nilai terendah 83 dengan \pm SD $89,48 \pm 4,102$, serta memiliki sebaran data yang terdistribusi normal $(\mathrm{Z}=0,144 ; \mathrm{P}=$ 0,128). Dan pada kelas Konvensional diperoleh nilai tertinggi 94 dan nilai terendah 82 dengan \pm SD 86,58 \pm 3,557, serta memiliki sebaran data yang terdistribusi normal $(\mathrm{Z}=0,171 ; \mathrm{P}=0,048)$. Pada telah memenuhi prasyarat uji normalitas dan pengujian hipotesis dapat dilakukan dengan uji nonparametrik

\section{PENGUJIAN HIPOTESIS}

Pengaruh Strategi Pembelajaran terhadap Sikap Ilmiah Siswa

Pengaruh strategi pembelajaran Problem Based Learning (PBL), Group Investigation (GI) dan Konvensional pada materi ekologi terhadap sikap ilmiah siswa dianalisis dengan menggunakan Analisis Kovariat (ANAKOVA). Hasil analisis dengan menggunakan bantuan SPSS 24.0 menunjukkan bahwa strategi pembelajaran Problem Based Learning (PBL), Group Investigation (GI) dan Konvensional berpengaruh signifikan terhadap sikap ilmiah siswa $(\mathrm{F}=3,673 ; \mathrm{P}=0,029)$

Maka secara keseluruhan terdapat pengaruh yang signifikan rata - rata sikap ilmiah siswa yang dibelajarkan dengan strategi 
pembelajaran Problem Based Learning (PBL), Group Investigation (GI) dan Konvensional pada materi ekologi, sehingga Ho2 tidak terdapat pengaruh yang signifikan penerapan strategi pembelajaran Problem Based Learning (PBL), Group Investigation (GI), maupun strategi pembelajaran Konvensional terhadap sikap ilmiah siswa di kelas X tentang ekologi di MAN kabanjahe ditolak. Dan Ha2 terdapat pengaruh yang signifikan penerapan strategi pembelajaran Problem Based Learning (PBL), Group Investigation (GI), maupun strategi pembelajaran Konvensional terhadap sikap ilmiah siswa di kelas $\mathrm{X}$ tentang ekologi di MAN kabanjahe diterima.

Hasil uji analisis dengan bantuan SPSS 24.0 menunjukkan bahwa sikap ilmiah yang dibelajarkan dengan strategi pembelajaran Problem Based Learning (PBL) dengan \pm SD 93,23 \pm 3,172 dan Group Investigation (GI) dengan \pm SD 89,48 \pm 4,102 lebih tinggi dibandingkan dengan strategi pembelajaran Konvensional dengan \pm SD 86,58 \pm 3,557 (Gambar 1).

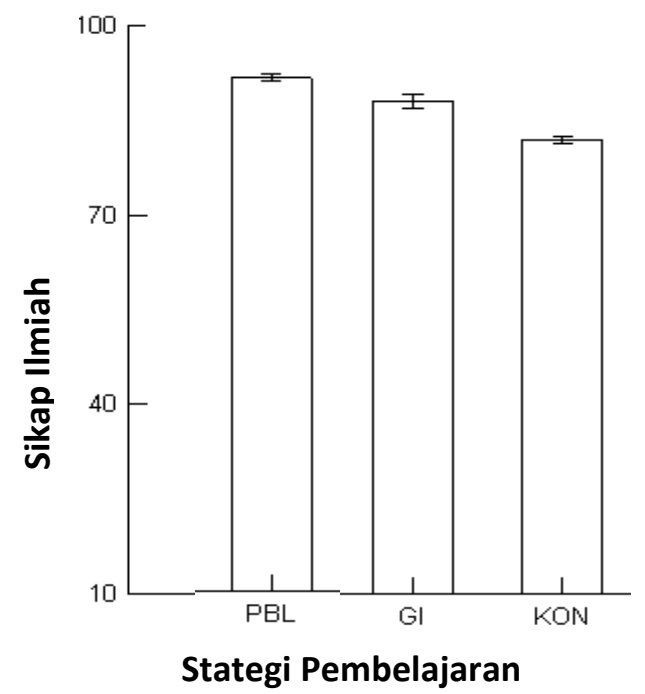

Gambar 1. Pengaruh Pembelajaran

Learning

Investigation

Konvensional Problem

Strategi (PBL), (GI)

Based Belajar Siswa tentang Ekologi di Kelas X MAN Kabanjahe.
Berdasarkan rata - rata nilai keterampilan proses sains siswa menunjukkan bahwa siswa yang dibelajarkan dengan strategi Problem Based Learning (PBL) memberikan pengaruh sebesar 7,68\% lebih tinggi dibandingkan dengan kelas yang dibelajarkan dengan kelas Konvensional. Kelas yang dibelajarkan dengan strategi Group Investigation (GI) memberikan pengaruh sebesar 3,34\% lebih tinggi dibandingkan dengan kelas yang dibelajarkan dengan strategi pembelajaran Konvensional.

\section{KESIMPULAN, IMPLIKASI DAN SARAN}

Berdasarkan hasil - hasil temuan penelitian dan analisis yang telah dilakukan oleh peneliti, maka diperoleh kesimpulan bahwa terdapat pengaruh yang signifikan strategi pembelajaran tipe Problem Based Learning (PBL), Group Investigation (GI) dan konvensional terhadap Sikap ilmiah biologi siswa pada materi ekologi kelas X pada MAN Kabanjahe. Hasil belajar siswa yang dibelajarkan dengan strategi pembelajaran Problem Based Learning (PBL) dengan nilai rata - rata 89,23 lebih tinggi dibandingkan dengan hasil belajar siswa yang dibelajarkan dengan strategi pembelajaran Group Investigation (GI) dengan rata - rata nilai 88,31 dan pembelajaran konvensional dengan nilai rata - rata 84,46.

\section{Implikasi}

Tingginya hasil belajar yang diajarkan dengan strategi Problem Based Learning (PBL) dan Group Investigation (GI) dikarenakan siswa lebih aktif dalam proses pembelajaran. Setiap siswa diharuskan mencari informasi dan memberikan informasi materi ekologi untuk dibagikan ke teman kelompok lain sehingga pemahaman siswa mengenai materi ekologi jauh lebih berkesan dibandingkan dengan pemahaman dan siswa yang dibelajarkan dengan pembelajaran konvensional yang hanya mendengarkan ceramah dari guru tanpa terlibat aktif dalam prose belajar mengajar.

Sikap merupakan hal penting dalam setiap diri siswa, dalam hal ini guru harus 
berperan lebih banyak agar sikap ilmiah dperlihatkan dalam setiap proses pembelajaran. Hasil pengujian hipotesis yang menunjukkan hasil yang adanya pengaruh yang signifikan antara strategi pembelajaran tipe Problem Based Learning (PBL), Group Investigation (GI) dan konvensional menunjukkan keberhasilan suatu proses belajar mengajar di sekolah. Keberhasilan belajar mengajar dapat diukur dalam bentuk nilai dan perubahan sikap dari siswa ke arah yang lebih baik dan juga siswa mampu mengingat pelajaran yang disampaikan guru dengan baik.

\section{Saran}

Berdasarkan simpulan yang telah dikemukakan, maka sebagai tindak lanjut dari penelitian ini disarankan beberapa hal sebagai berikut :

Sebelum proses belajar mengajar, hendaknya guru mampu menerapkan strategi pembelajaran tipe Problem Based Learning (PBL) maupun Group Investigation (GI) dan dapat merencanakan dengan langkah langkah /sintaks pembelajaran yang akan dilaksanakan sehingga proses pembelajaran di dalam kelas dapat berjalan sesuai dengan langkah - langkah strategi pembelajaran tersebut sehingga tujuan pembelajaran dapat tercapai dengan baik.

Dalam mengajarkan materi Ekologi, hendaknya guru mampu menyesuaikan strategi pembelajaran dan materi yang akan dipelajari, karena tidak semua strategi sesuai dengan materi Ekologi.

Kepada peneliti dan pemerhati pendidikan khususnya bidang biologi. Peneliti menyarankan kiranya para peneliti dapat melanjutkan penelitian tentang pengaruh penggunaan strategi pembelajaran terhadap hasil belajar, Sikap ilmiah dan sikap ilmiah siswa. Karena peneliti merasa hal ini penting untuk kemajuan pendidikan di Indonesia, khususnya di MAN Kabanjahe sehingga dapat bermanfaat sebagai penyeimbang teori dab acuan untuk penelitian selanjutnya.

\section{DAFTAR PUSTAKA}

Ahmad, H dan D.P.A Rubba. (1983). A Study Skill Achivment among A Sample Of High Ability Malaysian High School Graduates. Journal of science and mathematics in south East Asia, 6(1).

Departemen Pendidikan dan Kebudayaan. (1997). Kamus Besar Bahasa Indonesia.1997. Jakarta: Balai Pustaka.

Dick, W. And Carey, L. (2005). The Systematic Design of Instruction. Fourth edition. New York: Harper Colins Collage Publisher.

Kunandar. (2009).Langkah Mudah Penelitian Tindakan Kelas SebagaiPengembangan Profesi Guru. Jakarta. Raja Grafindo Persada.

Mutiara, C. (2011). Upaya Meningkatkan Hasil Belajar Biologi dengan Metode TPS Disertai Eksperimen pada Siswa SMAN 1 Batanghari Lampung Timur. Bioedukasi Volume 2, Nomor 1.

Oh, P.S \& M.K. Shin. (2005). Students' Reflections on Implementation of Group Investigation in Korean Secondary Science Classrooms. International Journal of Science and Mathematics Education. 3 (2): 327-349.

Panjaitan, B. (2006). Karakteristik Pembelajaran dan Kontribusinya terhadap Hasil Belajar. Medan: Poda.

Rusman. (2010). Strategi-Strategi pembelajaran: Mengembangkan Profesionalisme Guru. Jakarta: Raja Grafindo Persada.

Sanjaya, W. (2008). Strategi Belajar Berorientasi Standar Proses Pendidikan. Jakarta. Kencana.

Sari, D, P., Achmad, L., Ahmad, Q. (2013). Uji Coba Pembelajaran IPA Dengan LKS sebagai Penunjang Media Virtual Phet untuk Melatih Keterampilan Proses pada Materi 
Hukum Archimedes. FMIPA UNESA. Jurnal Pendidikan Sains ePensa, 01 (02) : 15 - 20.

Sudewi, Ni.L.,Saubagia,I.W.,Tika,I.N.(2014). Studi Komparasi Penggunaan Strategi Pembelajaran Problem Based Learning (PBL) dan Kooperatif Tipe Group Investigation (GI) Terhadap Hasil Belajar Berdasarkan Taksonomi Bloom. e-Journal Program Pascasarjana Universitas Pendidikan Ganesha Program Studi IPA (Volume 4 Tahun 2014).

Sudjana. (2005). Penilaian Hasil Proses Belajar Mengajar. Bandung: Remaja Rosdakarya.

Warsono \& Hariyanto. 2014. Pembelajaran Aktif: Teori dan Assesmen. Bandung: Remaja Rosdakarya.

Yunus, H.M. and Hashim, N.H. (2007). Science Process Skills Through English Language Skills Among Year One Pupils. Proceeding of International Conference on Science and Mathematics Education (CosMed) SEAMEO RECSAM Malaysia. 